\title{
Uncompensated Care: How Much is Too Much?
}

\author{
Zehra Hussain $^{1 *}$
}

\begin{abstract}
Texas is home to the largest uninsured population in the U.S. Such problems emerge, in large measure, from the state's rejection of Medicaid expansion. That decision has prevented Texas from receiving $\$ 100$ billion in federal cash over a decade. Consequently, the number of uninsured residents either going without local medical care or overloading adjacent communities is likely to increase. Therefore, this study seeks to explain the implications of Medicaid expansion in Denton county. This paper explores the effects of expanding Medicaid and how that would affect race, income, and Medicaid eligibility for indigent patients. The results of a Python-based simulation show that, adjusting for Denton's population growth at projected levels of uninsured, by 2020 the uncompensated care will cost Denton County $\$ 42,716,796$. This number will continue to rise to a total of $\$ 61,462,134$ as a result of ceasing Medicaid expansion and getting rid of the individual mandate. These numbers are important as they show the rising costs of uncompensated care that are associated with an increase in population growth.
\end{abstract}

\section{Keywords}

Uncompensated Health Care - Medicaid Expansion - Affordable Care Act — Denton, Texas

${ }^{1}$ Department of Political Science, University of North Texas

${ }^{\star}$ Faculty Mentor: Dr. Tom Miles

\section{Contents}

\section{Introduction}

1 Changes to Healthcare under Trump

1.1 High-Risk Pools . . . . . . . . . . . . . . . 2

1.2 Block Grant System . . . . . . . . . . . . . . . . 2

1.3 Increase in Age Ratio . . . . . . . . . . . . . 2

2 Data Analysis

3 Potential Solutions

4 Conclusion

5 Limitations

Author Biography

References

\section{Introduction}

Texas is home to the largest uninsured population in the U.S. Many of the 5 million uninsured Texan residents have no affordable option for health insurance-thus compounding illness, diminishing life expectancy, and increasing healthcare spending.[1] Meanwhile county hospitals incur $\$ 5.5$ billion in annual costs for treating uninsured people,[2] as federal law mandates that county hospitals may not turn away sick indigent patients. However, Dallas County public facility Parkland Hospital has been receiving a majority of the uninsured patients from surrounding counties, significantly increasing Parkland's uncompensated costs. Those counties send their own uninsured patients to other county hospitals to avoid local responsibility for care.
In 2015 the estimated cost of uncompensated care at Parkland Hospital was about \$816.5 million, of which \$388.7 million was charity care.[3] This expense rises yearly due to outof-county indigent patients receiving free healthcare. Such problems emerge, in large measure, from the state's rejection of Medicaid expansion. That decision has prevented Texas from receiving $\$ 100$ billion in federal cash over a decade.[2] This decision has resulted in uninsured residents either going without local medical care or overloading adjacent communities.

Pushing to expand Medicaid (as distinguished from Medicare here and below) throughout Texas would be cost-effective and extend coverage. Many state Medicaid agencies that adopted the Medicare-shared-savings program have the benefit of improving quality care, while building rapport with primary-care physicians, all while reducing costs. Bill Hammond, CEO of Texas Association of Business, argues that Medicaid expansion would annually save Texas businesses billions of dollars that could otherwise be invested productively. Studies have shown that every dollar the state would pay into Medicaid expansion would return $\$ 1.30$ in economic activity, topping out at \$3 billion.[2] Implementing Medicaidawareness programs would help 800,000 Texans, along with a great number of indigent patients become insured, would relieve county hospitals of the additional uncompensated care costs, and would eradicate the $\$ 36.2$ billion in federal taxes that Texas residents will pay over a decade for Medicaid expansion in other states.[4]

Although a majority of Texans favor of Medicaid expansion, Governors Rick Perry and Greg Abbot refused to enact Medicaid expansion in Texas. Both opposed federal funding, 
claiming that the initial $10 \%$ of the cost that the state would pay might eventually prove too much for the budget,[4] especially if the federal government were to cut back on the $90 \%$ it promises to pay. Since the Governor Perry's 15-member board of medical professionals recommended in 2014 that the state adopt Medicaid expansion, politics remains an obstacle to reform.

Additionally, the growth of Medicaid as a long-term care funding program has created some financial consequences. As Medicare actuaries expect Medicare spending to rise more rapidly in the coming years due to faster enrollment growth, an increase in service use, and faster growth in payment rates owing to higher prices brought about by a healthier economy,[5] Medicare's inability to finance long-term for an aging population places additional burden with the expansion of Medicaid. Such challenges will continue to be the subject of policymakers' attention, along further political divide.

\section{Changes to Healthcare under Trump}

Recently, the Trump administration repealed Obamacare's individual mandate under the new GOP tax bill. This means that the vast majority of Americans who are self-employed, who do not have access to employer insurance, or make too much money to qualify for safety net programs like Medicaid will face turmoil. This market, under the individual mandate, was created to widen risk pools to include a mix of young and old, health and sick, which ultimately drives the premiums down within this overall market. However, with the individual mandate being gone, will result in 13 million fewer Americans being insured in 2027.[6] Without this mandate, wealthier people may choose to forgo coverage and even indigent populations may not sign up for insurance because they are unaware of the options available since there is no sense of urgency to enroll. Additionally, the repealing of the individual mandate leads to exchanges being left with a sicker consumer pool, ultimately spiking up market premiums to $10 \%$.

\subsection{High-Risk Pools}

Under the new, "A Better Way" Republican healthcare plan, high-risk pools will be reinstated. These high-risk pools are a way for the government to provide subsidized health insurance to the patients that are dealing with illnesses ranging from diabetes to cancer, typically known as the most 'expensive' patients. The idea behind the high-risk pools is to give those patients coverage but while still keeping premiums lower for other, healthier patients by allowing the 'expensive' patients to be out of the insurance pool. Although the Republicans claim that these high-risk pools will help give the power back to the States to regulate their own programs, it actually is quite costly. Having the sickest patients in one pool will cause a State high-risk pool to have really high medical claims. This would be the biggest obstacle: the funding.

"Under the Republican plan, the federal government would allocate $\$ 25$ billion in health care reform legislation for state high-risk pools".[7] However, 35 states already had high-risk pools prior to the Affordable Care Act, and they spent a collective $\$ 2.5$ billion on health care in 2011 . This was mainly because such high-risk pools, even with double premiums, could not keep up to cover these large medical bills.[8] Therefore, it is estimated that the Republican health care bill would need another $\$ 200$ billion in high-risk pool funding, plus the $\$ 115$ it already appropriates in order to cover the 5\% of current small-group and individual market enrollees.[9] Additionally, the Congressional Budget Office estimates that states would not end up using most of the money allocated to them for these high-risk pools but rather to stabilize the individual market and dedicate their resources elsewhere. As a result, skepticism arises in regards to allowing states to use the money for other purposes. This, in turn, will be detrimental to developing the high-risk pools that the Republicans wish to reinstate.

\subsection{Block Grant System}

Furthermore, Trumpcare wishes to cease Medicaid expansion by changing the way the federal government gives money to the States through a so-called block grant. This means flexibility, but only in theory, as block grant funding does not account for rising costs. These changes under Trumpcare can affect Medicaid significantly. Medicaid funds most longterm care for the elderly, disabled, children, child births, as well as absorbs the costs for expensive coverage. If Trump's Medicaid funding limit plans are enacted, it may pave the way for overhauls of Medicare and Social Security, which are also facing serious financial shortfalls.

\subsection{Increase in Age Ratio}

It is important to note, however, that not all aspects of Trumpcare may negatively affect the economy. For example, under the ACA, premium ratings by age are permitted only if the ratio of the highest-cost adult age band to the lowest-cost adult age band does not exceed 3:1. Trumpcare seeks to raise the ratio to $5: 1$, which essentially means higher premiums for older adults and lower premiums for younger adults. According to the Milliman Research Report, 'Impact of Changing ACA Age Rating Structure,' which states that "younger APTCeligible adults therefore tend drop below their "fair share" contribution levels, leading to higher enrollment for adults ages 20-49...with an overall projected difference in 2018 individual market enrollment is an increase of $2 \%$ under a $5: 1$ versus a 3:1 age banding".[10]

\section{Data Analysis}

Therefore, this study seeks to explain the implications of Medicaid expansion in Denton county. I aim to explore the effects of expanding Medicaid and how that would affect race, income, and Medicaid eligibility for indigent patients. Through this, additional focus will be placed on uncompensated care costs. More specifically, if county hospitals are able to be less burdened with those costs if Texas opted to expand Medicaid. Furthermore, the other variables of race, income, and Medicaid eligibility, will seek to provide a bigger picture of 
those that will benefit within the Denton county. Thus, I hypothesize that ending the Medicaid expansion and the individual employer mandates increases uncompensated care in the coverage "donut hole," increasing uncompensated care by millions. This study uses Python to predict, based on previous data, the amount of uninsured individuals that will result from the gradual repeal of parts of the Affordable Care Act.

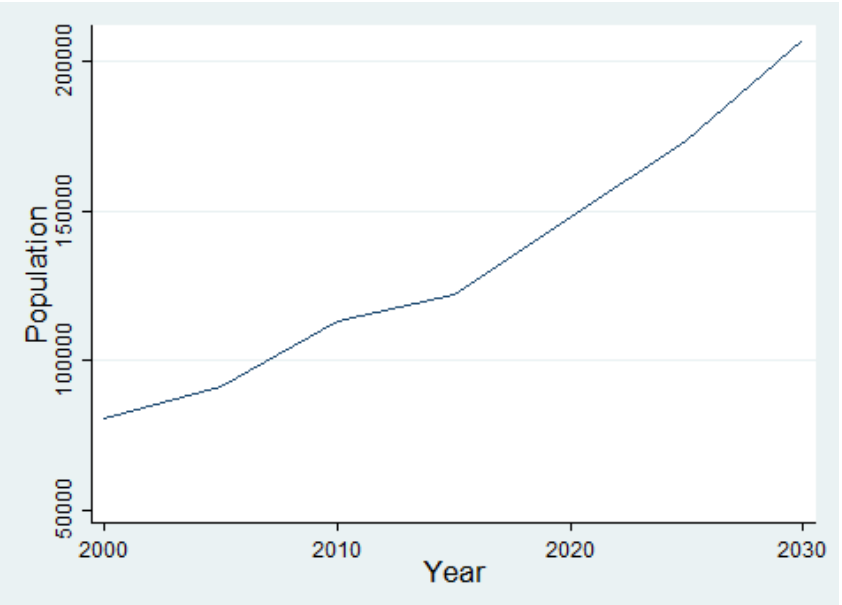

Figure 1. U.S. Census Bureau Estimates of Population Growth, Denton, Texas.

Figure 1 depicts Denton's population growth, which is projected to grow exponentially through the year 2030 with an increase of 200,000 people. This increase in growth can be attributed to many factors that are contributing to Denton's growth. Such factors include expansion of the University of North Texas, development of Rayzor Ranch, and more companies moving into the Dallas/Fort Worth area. This increase in growth also means more people for the Denton county hospitals to assume care for, which is important to look at when discussing the expansion of Medicaid effects.

Secondly, Figure 2 shows the increase in uninsured by income category in relation to the increase in population growth. It can be seen from Figure 2 that those who fall in the $250 \%$ below Federal Poverty Line (FPL) and those who fall in the $138 \%$ FPL are expected to rise as the most uninsured persons. These populations also lost Medicaid eligibility when the expansion ceased. Therefore, this seeks to show that those falling between $138 \%-250 \%$ below the FPL are most affected by the repeal of the individual mandate and will also be affected by Medicaid expansion. This data was achieved by using FPL data points and a 95\% confidence interval in order to predict the levels of uninsured based on historical trends.

Furthermore, through running the population amount of uninsured with the percentage of uncompensated care, the total healthcare expenditures numbers were found. For example, the uninsured receive less care per year, which amounts to \$2443 (Kaiser Family Foundation). However, of that \$2443 roughly $\$ 1702$ (69.67\%) of that care is uncompensated. Thus, adjusting for Denton's population growth at projected levels of uninsured, by 2020 the uncompensated care will cost Denton County $\$ 42,716,796$. This number will continue to rise to a total of $\$ 61,462,134$ as a result of ceasing Medicaid expansion and getting rid of the individual mandate. These numbers are important as they show the rising costs of uncompensated care that is associated with an increase in population growth.

\section{Potential Solutions}

The healthcare system of the United States if quite complex and has never really found a one-step solution. In order to help reduce some of these rising costs that are associated with a growing population, it will be beneficial to first recognize that there is indeed no one-step solution to solve these issues. For example, Medicaid expansion in states like Texas will surely be beneficial and can help reduce costs as well as input growth into the economy, however, that alone is not enough. Looking at community solutions and how other states utilize their healthcare resources can provide results that could be used in different settings. Furthermore, taking examples of how other countries choose to run their healthcare system can also be of usage. For example, the Netherlands utilizes a General Practitioner (GP) to screen all the patients first. This means that every person who is sick must first visit a GP, after which the GP will either determine the sickness and prescribe or refer you to a specialist if needed. In order to even receive an appointment with a specialist, one must first visit the GP. This screening method could help reduce the ER as primary costs as citizens are able to understand what the issue might be and could prevent more uncompensated care costs.

\section{Conclusion}

It was reflected in the estimated costs of total healthcare expenditures that my hypothesis proved to be correct, that ending the Medicaid expansion and the individual and employer mandates will increase uncompensated care.

The rising cost of healthcare in the United States is not only placing additional burdens on its citizens but also on the county hospitals and those that they serve The people that are offsetting the uncompensated care costs are the citizens as well as Texas businesses. Therefore, expanding Medicaid within the state of Texas can help reduce these uncompensated care costs that are expected to rise exponentially with the growth of the population. Access to adequate healthcare is a universal human right and therefore should be treated as such.

\section{Limitations}

There were a few limitations that was experienced when conducting the research component of this topic. Firstly, gathering uncompensated care costs for any Denton county hospital proved to be a huge challenge. Surprisingly, this uncompensated care cost data is not readily available like it is for other counties such as Dallas county. After opening up multiple lines of communication with public health and county hospital officials and not hearing back, this unsuccessful feat was 


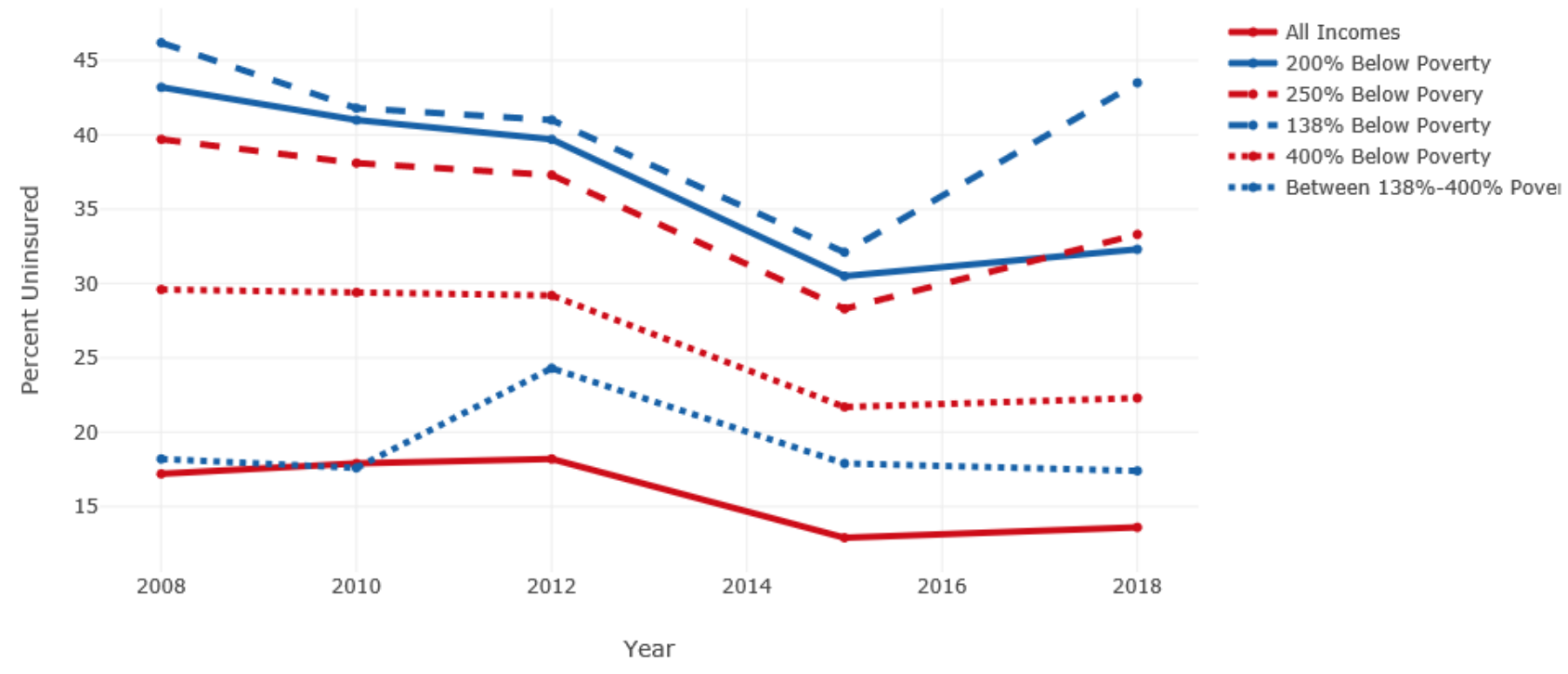

Figure 2. Projected Number of Uninsured, Denton, Texas.

indeed a limitation. It also seeks to show that perhaps this data is not readily available because Denton county may not want their constituents to find out this information. Also, Dallas county hospital, Parkland Hospital, receives a lot of indigent patients from Denton county. This could also explain the reasoning behind an unsuccessful response from these county officials.

\section{Author Biography}

Zehra Hussain graduated from University of North Texas in 2018. She plans to attend medical school and pursue a career in medicine and hospital administration.

\section{References}

[1] Ruben Amarasingham. Advanced models for health hearing. Www. healthIT.gov. Accessed: 2018-06-16.

[2] Wade Goodwyn. Texas loses billions to treat the poor by not expanding medicaid, advocates say. WWW . healthIT.gov. Accessed: 2018-06-15.

[3] Parkland Hospital System. Report: Dallas county hospital district. WWW.parklandhospital.com/ Uploads / Public/Documents/PDFs/Reports. Accessed: 2018-07-18.

[4] Louise Norris. Texas and the aca's medicaid expansion: Eligibility, enrollment and benefits. WWW . healthinsurance.org/texas-medicaid/. Accessed: 2018-06-12.
[5] Patricia Neuman and Juliette Cubanski. Medicare part d update-lessons learned and unfinished business, 2009.

[6] Congresssional Budget Office. Repealing the Individual Health Insurance Mandate: An Updated Estimate. Washington, DC, Congressional Budget Office, 2017.

[7] Trumpcare Health Network. Reinstating high-risk pools-is it a good idea? www.trumpcare.com/ reinstating-high-risk-pools-is-it-a-good-idea. Accessed: 2018-07-18.

[8] Sarah Kliff. High-risk pools: the newest proposal to fix the gop's health plan, explained. Vox, 3:18, 2017.

[9] Sam Berger and Emily Gee. Latest ACA Repeal Plan Would Explode Premiums for People with Pre-Existing Conditions. Washington, DC, Center for American Progress, 2017.

[10] Joanne Fontana. Impact of changing aca age rating structure. www.milliman. com/aarp/. Accessed: 201805-13. 